\title{
NOTE ON THE VOLATILITY OF BORIC ACID; SEPARATION OF BORIC FROM PHOSPHORIC ACID; ESTIMATION OF BORIC ACID IN FOODS.
}

BY L. DE KONINGH.

March I. 2897.

W ${ }^{\text {HEN titrating boric acid with standard soda, any alkali }}$ and the solution well boiled to expel any carbon dioxide. As it is generally believed that boric acid is volatile and escapes with the aqueous vapors, it was thought worth while to ascertain in how far this is serious enough to interfere with accurate analysis. Some chemists advise boiling under an upright condenser, but the writer doubts whether one gets really rid of the carbon dioxide, which is the great enemy when titrating with phenolphthalein as indicator. In the first set of experiments two grams of commercial boric acid were dissolved up to one liter. One hundred cc. were mixed with fifty cc. pure glycerol, phenolphthalein was added and two-tenths normal soda was run in until a permanent red coloration was obtained, which took place after adding 16.3 cc. One hundred cc. were now boiled for five minutes, and after cooling, made up again to $100 \mathrm{cc}$, , sixteen cc. having evaporated. This time I6. I cc. of the soda were required. One hundred cc. were again boiled, this time for ten minutes, the loss being fifty cc.; $16.0 \mathrm{cc}$. of soda were required. In a third experiment the boiling lasted fifteen minutes, the loss amounting to sixty cc.; sixteen cc. of soda were consumed. These three experiments were conducted in a narrow-necked conical flask; the fourth experiment was therefore conducted in a large beaker, boiling for fifteen minutes, the loss now amounting to eighty $\mathrm{cc}$.; sixteen cc. of soda were required.

In the second set of experiments two grams of boric acid were dissolved with the aid of fifty grams of dry sodium carbonate and the solution made up to one liter. One hundred cc. were colored with methyl orange and slightly acidified with hydrochloric acid. After boiling for three minutes the loss amounted to three cc. After cooling the liquid was carefully neutralized and then mixed with fifty cc. of glycerol. After adding phenolphthalein I $6.6 \mathrm{cc}$. of approximately two-tenths normal soda were required. Another $100 \mathrm{cc}$. were treated in the same way, the boiling last- 
ing ten minutes, and the loss amounting to thirty-seven cc., when $\mathrm{r} 6.6 \mathrm{cc}$. of soda were required. In a third experiment the boiling was continued for fifteen minutes, the loss amounting to sixty cc.; again I6.6 cc. of soda were required. From these experiments, it may be safely concluded that dilute solutions of boric acid may be boiled down to a small bulk without any loss of the acid.

To see what the loss would amount to if actually evaporated to dryness, two portions of $100 \mathrm{cc}$. each, one with addition of some sodium silicate, were mixed with a large excess of hydrochloric acid and the mixture treated as in a silicate analysis. After dissolving in about roo cc. of water and removing the trace of free acidity, the one with the silica added took 14.8 and the other I $3.6 \mathrm{cc}$. of soda. It is, therefore, plain that when nearly dry a considerable loss takes place by volatilization, but it is much less than some authors would have us believe.

SEPARATION OF BORIC FROM PHOSPHORIC ACID.

It has been pointed out in a previous communication ${ }^{2}$ that the great, if not the only, drawback of using the titration process for estimating the boric acid in foods, is the invariable presence of phosphoric acid in the ash of the same. It may, therefore, be argued that once given a good process for removing phosphoric acid, the estimation of boric acid in foods may be considered as completely solved for the present. Thomson, ${ }^{2}$ the inventor of the titration process, has proposed using barium chloride, but has to my knowledge never finished his researches in that direction. Another writer has proposed using calcium chloride, and this may be used with some success as follows: The solution must contain a slight excess of sodium carbonate. On cautiously adding calcium chloride, any phosphate, and also the excess of carbonate, is precipitated, while the borate in very dilute solution is not precipitated at all. On now adding solution of ammonium carbonate containing excess of ammonia, the excess of lime is precipitated and the filtrate contains boric acid with free ammonia and ammonium chloride. By boiling with due excess of sodium carbonate the ammonia compounds are soon expelled, as the liquid contains an alkaline borate which is then titrated as directed. 
One hundred $\mathrm{cc}$. of the solution mentioned in the first set of experiments were mixed with ten drops of saturated solution of sodium phosphate. It finally took $\mathrm{I} 6.3 \mathrm{cc}$. of soda solution, showing the method to be accurate. The separation by means of magnesia mixture was also tried. Another $100 \mathrm{cc}$. of the solution were acidified with hydrochloric acid and then mixed, as usual, with slight excess of magnesia mixture, ten drops of sodium phosphate solution having been previously added. After some hours the liquid was filtered and then mixed with about five grams of sodium carbonate. On warming, the bulk of the magnesia was at once precipitated and filtered off to prevent bumping. The liquid was now rapidly boiled down to expel ammonium compounds, and finally evaporated to dryness to render the magnesia insoluble. After taking up with a little water and filtering, the result finally was $\mathrm{I} 6.2 \mathrm{cc}$. of soda solution.

ACTION OF AMMONIACAL SOLUTION OF ZINC OXIDE ON BORIC ACID.

If boric acid is mixed with large excess of zinc oxide dissolved in ammonia, and then evaporated until no more ammonia is given off, the separated matter seems to be pure zinc oxide; at all events when dissolved in sulphuric acid and mixed with alcohol the latter does not burn with a green flame; the filtrate also gives no precipitate with ammonium sulphide. Fifty cc. of the first boric acid solution treated with ammoniacal zinc took finally eight $\mathrm{cc}$. of soda. Experiments are being made, but as yet without much success, in rendering this a process for the separation of the phosphoric acid, which as we know forms an insoluble compound with zinc. Now the question arises: Can one, without hesitation, recommend the titration process as fit for the estimation of boric acid in foods? In a few experiments in which one-tenth gram of crystallized boric acid (dissolved in soda-lye) was introduced into roo grams of oatmeal, $0.095 \mathrm{gram}$ was recovered by the magnesia separation ; but the word "food" comprises such a variety of bodies that in some cases unexpected difficulties may turn up. However, the writer intends always using it when opportunity arises, and by adding a known extra weight of the acid to another portion of the substance under examination, hopes before very long to bring forward a 
further series of experiments; and in the meanwhile invites others to do the same and to publish their results in this Journal.

\title{
METHOD OF DRYING SENSITIVE ORGANIC SUBSTANCES.'
}

\author{
By C. C. Parsons. \\ Received March 18,5897 .
}

SOME years ago in preparing formulas for a class of deter$\checkmark$ gent compounds, of which soap was one of the ingredients, it was necessary, in order that the formula should be exact and definite, to ascertain the moisture in a great number of soaps, as commercial soaps differ greatly in this particular.

The usual processes described in analytical works were slow, and, unless very carefully conducted, were liable to cause decomposition of the soap by overheating.

Some previous experiments in dissolving soaps in mineral oils for increasing their viscosity and lubricating quality, suggested using an oil-bath, putting the soap directly into the hot oil, and weighing before and after the hot oil had driven off the moisture. It worked very satisfactorily, and subsequently was used with equally good results for drying wood paper pulp in some investigations in nitrating it for a smokeless powder.

The process has not been used extensively for commercial analysis, but in factory operations it has been used continually for some years, and could possibly be applied to drying many other substances.

In practice the best results have been obtained by using what is commercially called a straight paraffin oil, that is without any mixture of animal or vegetable oils or fats, or mineral substances, perfectly neutral, 0.920 specific gravity $\left(22.5^{\circ}\right.$ B. $), 435^{\circ}$ flash test, $500^{\circ}$ fire test, about $55^{\circ}$ boiling-point. The object of a high fire test is that the oil will be so freed from volatile matter that none of it will be carried off with the moisture in the substance to be dried.

If many such analyses are required, it is advisable to prepare enough oil for several operations by heating it to about $250^{\circ}$ for some time, and then keep it in a closed vessel, as it absorbs moisture from the air when exposed. A suitable amount of the sub-

1 Read at the Meeting of the New York Section, March 5, I897. 